\title{
Mandatory reporting of "imminent" death to identify organ donors: history, controversy, and potential solutions
}

\author{
[Déclaration obligatoire de mort "imminente" pour identifier des donneurs d'or- \\ ganes : histoire, controverse et solutions possibles]
}

Peter Dodek MD MHSC

Purpose: To review the history of mandatory reporting for the purpose of identifying potential organ and tissue donors, and the controversy around the terms, "imminent" or "impending" death, and to suggest a solution to this controversy.

Source: In this narrative review, published papers were retrieved based on a Medline search using the terms, "mandatory reporting" and "organ donation." In addition, unpublished data from the United Network for Organ Sharing and the Pennsylvania Gift of Life Program were reviewed.

Principal findings: There has been no demonstrable effect of mandatory reporting of "imminent" death independent of educational activities on numbers of organ donors or organs transplanted. Furthermore, mandatory reporting of "imminent" death does not meet criteria of an acceptable screening test.

Conclusion: Education of health care providers about eligibility for organ and tissue donation and about whom to report as a potential donor will hopefully lead to identification of more individuals who meet criteria for organ donation and who will go on to donate organs to the many potential recipients.

Objectif : Revoir l'historique d'une déclaration obligatoire visant à identifier des donneurs d'organes et de tissus potentiels et la controverse autour des termes de mort "imminente" ou "annoncée" et suggérer une solution.

Source : Dans cette revue descriptive, des articles publiés ont été extraits de la base de Medline à partir des termes "mandatory reporting" et "organ donation". Nous avons aussi passé en revue les données non publiées du United Network for Organ Sharing et du Pennsylvania Gift of Life Program.
Constatations principales: II n'y a pas d'effet démontrable de la notification obligatoire de mort "imminente", indépendante des activités pédagogiques, sur le nombre de donneurs d'organes ou d'organes transplantés. De plus, l'obligation de déclarer la mort "imminente" ne répond pas au critère d'un test de dépistage ou d'un procédé de sélection acceptable.

Conclusion : La formation des prestateurs de soins sur l'admissibilité d'un don d'organe et de tissus et sur les gens reconnus comme donneurs potentiels devrait, espérons-le, conduire à l'identification de plus d'individus, répondant aux critères de don d'organe, qui acceptent de faire un don aux nombreux receveurs potentiels.

$\mathrm{T}$ $\mathrm{O}$ address the gap between the number of individuals waiting for organ transplants and the number of organ donors, policy makers and organ procurement organizations (OPOs) have proposed and implemented several strategies over the last 20 years. One of the most recent strategies is the mandatory reporting of all deaths and "imminent" or "impending" deaths by acute care hospitals to OPOs. The purpose of reporting deaths is to identify potential tissue donors and the purpose of reporting "imminent" deaths is to identify potential organ donors. However, "imminent" death does not necessarily equate to brain death and therefore to the eligibility for organ donation. The purpose of this article is to review the history of mandatory

From the Program of Critical Care Medicine and Centre for Health Evaluation and Outcome Sciences, St. Paul's Hospital and University of British Columbia, Vancouver, British Columbia, Canada.

Address correspondence to: Dr. Peter Dodek, Intensive Care Unit, St. Paul's Hospital, Centre for Health Evaluation and Outcome Sciences, 1081 Burrard Street, Vancouver, British Columbia V6Z 1Y6, Canada. Phone: 604-806-9023;

Fax: 604-806-8674; E-mail: pedodek@interchange.ubc.ca

Funding: none. Conflicts of interest: none known.

Accepted for publication March 17, 2003.

Revision accepted July 2, 2003. 
reporting and the controversy around the terms, "imminent" or "impending" death, and to suggest a solution to this controversy.

\section{History}

Since 1985, all acute care hospitals in 49 states and the District of Columbia in the USA have been required by law to have a protocol for identifying potential organ donors, and to have a procedure whereby trained personnel request organ donation when a patient meets the criteria for organ donation (death or brain death). Introduction of this "required request" law increased the number of referrals transiently in some jurisdictions ${ }^{1}$ but had little effect on the number of actual organ donors ${ }^{1-3}$ in part due to the continuing low rate of consent from families. ${ }^{4}$ This lack of effect has been explained by inadequate education of requesters, inconsistency in criteria for organ donation among OPOs, and an objection on the part of health care providers to notifying OPOs before approaching families. ${ }^{5}$ Furthermore, required request creates conflicts of interest at clinical, psychological, and social/economic levels. ${ }^{6} \mathrm{~A}$ clinical conflict of interest is created because the clinician who is caring for a patient may be the same person who requests organ donation. A psychological conflict of interest is created because families of potential organ donors are in the midst of grief and a sense of loss at the same time as they are being asked to donate their relative's organs. A social/economic conflict of interest is created because OPOs cannot survive economically without organ donation.

In the early 1990s, a new strategy called mandated choice was proposed, ${ }^{7,8}$ and supported by the American Medical Association. ${ }^{9}$ This strategy would require individuals to express their preference regarding organ donation through an official channel such as at the time of renewing their driver's license. A mandatory choice law was introduced in Texas in 1991 but was withdrawn in 1997. In that state, mandatory choice was associated with a refusal rate of $80 \%$; this high refusal rate may have been due to difficulties in making a choice about the future and the fear that agreeing to be a future organ donor might compromise necessary care in a medical crisis. ${ }^{10}$ A variation on this strategy has been proposed in which individuals are given three choices to the question of organ donation: yes, no, and let others decide. ${ }^{11}$ Other strategies such as offering financial incentives for families of donors and presumed consent remain controversial and have not been introduced in North America. ${ }^{10}$

In 1994, the state of Pennsylvania passed Act 102 - a law that requires all hospitals to report all deaths and all cases of terminal brain injury before the declaration of brain death. Failure to report is associated with a fine to the hospital of $\$ 500$ per case. "Terminal brain injury" is defined through cooperative understandings among key physicians and other health providers at each hospital (personal communication, Howard Nathan, President and CEO, Gift of Life Donor Program). This law also requires that the OPO determine donor suitability for organ or tissue donation and that the request for organ and/or tissue donation be made by the OPO staff in cooperation with hospital staff. This component of the law was based on observations that consent rates were highest when requests were made jointly by OPO and hospital staff compared to OPO staff alone or hospital staff alone. The implementation of this law was accompanied by a stunning educational program. During the first 18 months, more than 1,800 educational meetings were held on this subject in 130 hospitals. During the next five years, approximately 1,600 additional educational meetings and conferences were held with physicians in attendance (personal communication, Howard Nathan). During the first year after introduction of this law (1996), referrals increased by 18 -fold and the number of organ donors increased by $26 \%{ }^{12}$ Despite requests by specially trained staff, the refusal rate remained constant at $52 \%{ }^{12}$ Between the introduction of this law in 1995, and 1999, organ donations increased by $59 \%$ from 208 to 331 per year and organ transplants increased by $63 \%$ from 606 to 1,005 per year in Pennsylvania (personal communication, Howard Nathan).

In August 1998 the US Health Care Financing Administration (HCFA) implemented a regulation similar to Pennsylvania Act 102 called the Medicare and Medicaid Hospital Conditions of Participation for Organ, Tissue, and Eye Donation. These conditions require all hospitals participating in the Medicare/Medicaid programs to refer all deaths and imminent deaths to their local OPO for determination of suitability for organ donation. Initially the definition of the term, "imminent" was left open for hospitals and OPOs to determine. Subsequently, the office of Clinical Standards and Quality of HCFA issued the following guideline for the definition of "imminent death:"

"A patient with severe, acute brain injury: Who requires mechanical ventilation; Is in an Intensive Care Unit or Emergency Department; and

Has clinical findings consistent with a Glasgow Coma Score that is less than or equal to a mutually-agreed-upon threshold; or 
For whom physicians are evaluating a diagnosis of brain death; or

For whom a physician has ordered that life sustaining therapies be withdrawn, pursuant to the family's decision." 13

In the same document, HCFA stated:

"We urge OPOs and hospitals to work together to develop a definition for "imminent death" that strikes a balance between the needs of the OPO and the needs of the hospital's care givers to continue treatment of a patient until brain death is declared or the patient's family has made the decision to withdraw supportive measures. Collaboration between OPOs and hospitals will create a partnership that furthers donation, while respecting the perspective of the hospital staff." 13

Although the conditions of participation were implemented only recently in 1998, there has been no significant increase in the number of organ donations or organ transplants in 2000 compared to the nine years prior. ${ }^{14,15}$ Similarly, there has been no change in the trend for numbers of patients waiting for an organ transplant or the number of deaths of patients waiting for an organ transplant. ${ }^{14}$

\section{Controversy}

In 1998, the British Columbia legislature passed an amendment to the Human Tissue Gift Act which stipulated that all hospitals must notify the B.C. Transplant Agency (currently through an agency in Colorado) of all deaths and "impending" deaths for all patients age 75 or less. This notification involves the provision of information about these patients including their name, age, diagnoses, and risk factors for blood borne infections. The intention is to use this notification as a screen for possible organ donors. The problem with this approach is that "impending" is not defined in the amendment and the closest semblance of a definition appears in the summary hospital pathway in which the triggers of a potential donor and notification are:

"Less than or equal to $75 \mathrm{yr}$ old;

Any medical event leading to significant, untreatable alterations in cerebral blood or oxygen flow and death is imminent;

Any acute medical illness, which is untreatable and death is imminent." A

It is highly likely that nearly all physicians and nurses in B.C. are strong supporters of organ and tissue dona-

\footnotetext{
A B.C. Transplant Society. Universal Referral and Training Resource Package. B.C. Transplant Society; 1999.
}

tion for the purposes of transplantation and that they agree with the aim of the legislation in B.C. which is "to facilitate increased levels of organ donation and transplantation." It is also important to note that in B.C., an essential criterion for organ donation is brain death and that there are clear objective criteria for the determination of brain death. Given the lack of clear definition of "imminent" or "impending" in the B.C. legislation or regulations, the B.C. Transplant Society was asked for assistance. One of their officials responded, " "imminent death" refers to the potentially brain dead individual" and that "notification should occur when it is determined that nothing more medically or surgically can be done for the individual." Unfortunately, this response does not help providers in their daily care of very ill patients. The current interpretation of the legislation by the B.C. Transplant Society requires that health care providers must report many patients who will die a cardiopulmonary death without a period of brain death (e.g., withdrawal of mechanical ventilation in a conscious patient who has end-stage chronic obstructive lung disease or withdrawal of life support in a patient who has multi-system organ failure due to sepsis but who is not brain dead). Many issues arise from a lack of definition of "imminent" or "impending" death:

Reporting individuals as potential organ donors who are not brain dead creates a conflict for the health care providers: are they the advocate for the patient under their care, or the advocate for the organ retrieval agency?

Sustaining patients on mechanical ventilation while waiting for an assessment from the B.C. Transplant Agency and potentially waiting for brain death to occur (the next step), is non-therapeutic (elective) ventilation.

Non-therapeutic ventilation is problematic from a clinical perspective because the natural history of severe brain injury is not necessarily predictable and the end-points of this procedure if brain death does not occur are also unpredictable (and may not be desirable).

Non-therapeutic ventilation is problematic from both an ethical and legal perspective because informed consent for this procedure cannot be obtained and it may constitute battery in the absence of consent.

Reporting individuals as potential organ donors who are clearly not going to become brain dead before cardiopulmonary death is a source of unnecessary and avoidable fear and anxiety for patients and their loved ones.

Given the purpose of the legislation, it is important to ask, what is the magnitude of the problem? How many 
potential organ donors do we currently identify from the pool of eligible individuals? Is this a generalized or focal problem? Therefore, should the strategy to increase "levels of organ donation" be targeted or generalized? We have no explicit answers to these questions.

The strategy that has been legislated is mass screening for potential organ donors. This strategy is comparable to asking physicians to refer all men and women to a central agency because they might be candidates for heart surgery. Instead, we educate health providers about risk factors and warning signs - then, referral is selective based on high yield of return. There is no evidence to indicate that universal referral of deaths and "imminent" deaths is superior to an intensive, multi-pronged, and targeted educational program - in terms of effectiveness and efficiency.

It may be useful to examine this mass screening strategy using the classic criteria for appraising screening ${ }^{16}$ from the World Health Organization.

a) "The condition sought should be an important health problem"

There is no doubt that provision of organs and tissues to potential recipients from suitable donors who meet all of the criteria for organ or tissue donation is an important health problem.

b) "There should be an accepted treatment for patients with recognized disease"

In this case, the "treatment" is harvesting of organs and tissues from individuals who meet all criteria for organ or tissue donation. These procedures are well-accepted.

c) "Facilities for diagnosis and treatment should be available"

Diagnosis of brain death or clinical death (cardiopulmonary death) can be done in existing health care facilities. Except for the necessity of transfer in some cases, there is no problem with availability of facilities for organ transplantation.

d) "There should be a recognizable latent or early symptomatic stage"

In the case of identifying potential donors of tissues, this criterion is irrelevant because the donors are identified after death. In the case of identifying potential donors of solid organs, this criterion is also irrelevant if we consider only patients who already meet criteria for brain death and who have no obvious exclusions to organ donation. However, the problem arises in screening patients who do not currently meet criteria for brain death because there are no specific predictors of who will become brain dead within a time frame that will allow for procurement of organs. There is no specific "recognizable latent or early symptomatic stage" of brain death. e) "There should be a suitable test or examination"

There are suitable tests to confirm clinical death and brain death (according to widely accepted criteria) but there is no published "suitable test or examination" that will predict the development of brain death with high predictive values (both positive and negative). Universal reporting of all deaths and "imminent deaths" is not a "suitable test or examination" because it lacks specificity.

f) "The test should be acceptable to the population"

Declaration of brain death or clinical death seems to be acceptable to the population. Definitions of these states have been developed by national and international professional groups who have at least some public representation. However, there is no evaluation of universal referral to determine if this approach to identifying potential organ donors is acceptable to the population, especially the population in B.C. There was no consultation with a cross-section of the citizens of B.C. in advance of the passage of this legislation.

g) "The natural history of the condition, including development from latent to declared disease, should be adequately understood"

Here is the main problem with universal referral, especially of patients who do not meet criteria for brain death. The natural history of "imminent death" can hardly be understood without a definition of "imminent death." See also the points raised in section "e" above.

h) "There should be an agreed policy on whom to treat as patients"

In this case, the "policy on whom to treat" means the criteria for eligibility as an organ or tissue donor. Clarity of these criteria and education about these criteria to health providers who care for these patients might increase the number of potentially eligible organ and tissue donors. This kind of strategy has been used successfully in many other screening programs and in the Pennsylvania Gift of Life Program.

i) "The cost of case-finding (including diagnosis and treatment of patients diagnosed) should be economically balanced in relation to possible expenditure on medical care as a whole"

There has not been an economic assessment of universal referral. Given the multiple steps in the referral process and the additional work to be done by 'front-line' health providers, and the potential number of donors as a fraction of the total number of deaths 
and "imminent deaths," citizens might wonder if this is the best way to manage our resources. There are probably much more targeted and efficient ways to achieve the same or better outcome.

j) "Case-finding should be a continuing process and not a 'once and for all' project"

Once an effective and efficient process for identification of potential organ donors has been developed, it would probably be supported as a "continuing process."

In summary universal referral of all deaths and "imminent" deaths does not meet the accepted criteria for a valid screening test.

\section{Potential solutions}

Given that the dictionary definition of "imminent" is "hanging threateningly over one's head," 17 it would be reasonable to define "imminent" death accordingly. One such definition could be, "meets all criteria for brain death and is awaiting second confirmatory physical examination." Therefore, suggested language for medical advisory committees and other hospital committees that are grappling with this problem could be:

Whereas:

1) Physicians and nurses at Hospital are strong supporters of organ and tissue donation for the purpose of transplantation, and of improving processes to identify potential organ donors;

2) The primary ethical and legal responsibility of the intensive care unit (ICU) physician is to the ICU patient. ICU physicians have additional responsibilities to society as a whole, and to patients in need of organ and tissue transplantation, but these responsibilities must not compromise the ICU physician's primary responsibility;

3) Donation of solid organs (except kidneys from related donors) requires that the donor be brain dead according to explicit criteria; and

4) The terms, "imminent death" and "impending death" in the context of Amendments to the Human Tissue Gift Act of 1998 (or similar Act) are not defined explicitly;

It is moved that terms, "imminent death" and "impending death" in the context of Amendments to the Human Tissue Gift Act of 1998 (or similar Act) will be defined at Hospital as the situation in which a patient meets all criteria for brain death and is awaiting a second confirmatory physical examination.

\section{Summary and conclusion}

Strategies are needed to improve the identification of potential organ donors. Mandatory reporting of "imminent" or "impending" deaths is problematic because "imminent" and "impending" are not clearly defined. Using the World Health Association criteria for definition of a useful screening test, mandatory reporting fails. Education of health care providers about eligibility for organ and tissue donation and about whom to report as a potential donor will hopefully lead to identification of more individuals who meet criteria for organ donation and who will go on to donate organs to the many potential recipients.

\section{Acknowledgement}

The author is grateful to Dr. Graeme Rocker for his thoughful review of this manuscript.

\section{References}

1 Ross SE, Nathan H, O'Malley KF. Impact of a required request law on vital organ procurement. J Trauma 1990; 30: 820-4.

2 Norris $M K$. Required request: why it has not significantly improved the donor shortage (Editorial). Heart Lung 1990; 19: 685-6.

3 Gaber AO, Hall G, Britt LG. An assessment of the impact of required request legislation on the availability of cadaveric organs for transplantation. Transplant Proc 1990; 22: 318-9.

4 Siminoff LA, Arnold RM, Caplan AL, Virnig BA, Seltzer $D L$. Public policy governing organ and tissue procurement in the United States. Results from the national organ and tissue procurement study. Ann Intern Med 1995; 123: 10-7.

5 Caplan AL, Virnig B. Is altruism enough? Required request and the donation of cadaver organs and tissues in the United States. Crit Care Clin 1990; 6: 1007-18.

6 Martyn S, Wright R, Clark L. Required request for organ donation: moral, clinical, and legal problems. Hastings Cent Rep 1988; 18: 27-34.

7 Spital A. Mandated choice. The preferred solution to the organ shortage? Arch Intern Med 1992; 152: 2421-4.

8 Spital A. Mandated choice. A plan to increase public commitment to organ donation. JAMA 1995; 273 : 504-6.

9 Council on Ethical and Judicial affairs, American medical association. Strategies for cadaveric organ procurement. Mandated choice and presumed consent. JAMA 1994; 272: 809-12.

10 Arnold RM, Siminoff LA, Frader JE. Ethical issues in organ procurement. A review for intensivists. Crit Care Med 1996; 12: 29-48.

11 Herz SE. Two Steps to three choices: a new approach to mandated choice. Camb Q Healthe Ethics 1999; 8: 340-7.

12 Pollard $S$. The impact of state legislation on organ 
donation-results of a US pilot scheme. Nephrol Dial

Transplant 1997; 12: 2510-1.

13 Identification of potential organ, tissue, and eye

donors. Questions and answers.

http://www.cms.hhs.gov/cop/2a2.asp

14 UNOS 2001 Annual Report of the U.S. Organ

Procurement and Transplantation Network and the

Scientific Registry for Transplant Recipients: transplant

Data 1991-2000. Department of Health and Human

Services, Health Resources and Services

Administration, Office of Special Programs, Division of

Transplantation, Rockville, MD; United Network for

Organ Sharing, Richmond, VA; University Renal

Research and Education Association, Ann Arbor, MI.

15 Marks WH. Participating in organ and tissue donation.

Surgical Services Management 1999; 5: 48-50.

16 Wilson JMG, Jungner G. Principles and Practice of

Screening for Disease. World Health Organ; 1968.

17 Woolf HB. The Miriam-Webster Dictionary. New York:

Pocket Books; 1974.

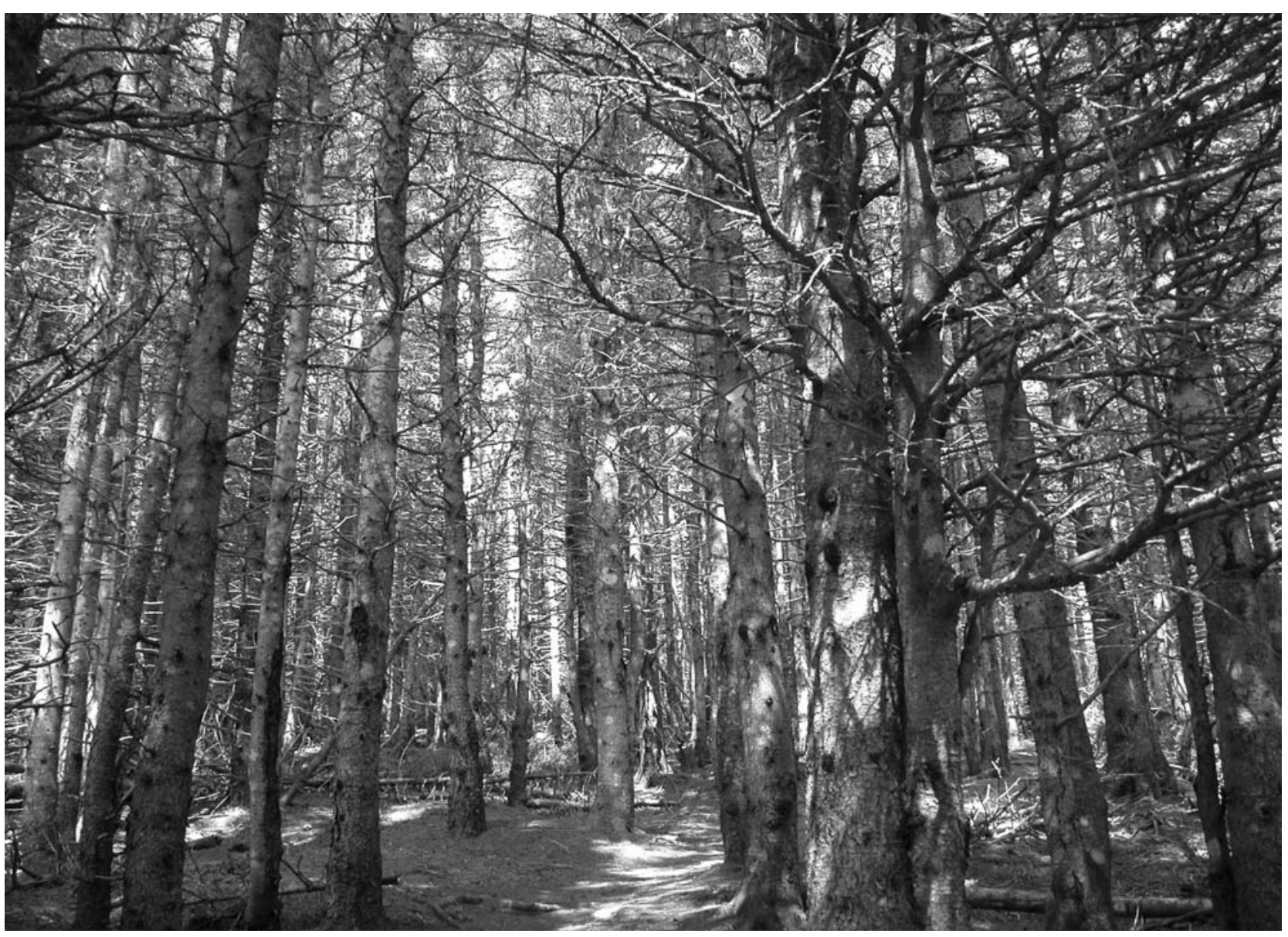

Parc Forillon - Québec 